\title{
Report on the Expert Forum on Using Information Technology to Facilitate Uptake and Impact of Colorectal Cancer Screening Guidelines
}

\author{
Maida J Sewitch $\mathrm{PhD}^{1,2,3}$, Mengzhu Jiang MSc${ }^{2}$, Alan N Barkun MD MSc ${ }^{1,3}$, David Armstrong MA MB BChir ${ }^{4}$,

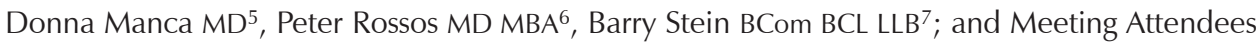

\begin{abstract}
MJ Sewitch, M Jiang, AN Barkun, et al; and Meeting Attendees. Report on the Expert Forum on Using Information Technology to Facilitate Uptake and Impact of Colorectal Cancer Screening Guidelines. Can J Gastroenterol 2012;26(12):902-904.

The present report summarizes the proceedings of the pan-Canadian Expert Forum on Using Information Technology to Facilitate Uptake and Impact of Colorectal Cancer Screening Guidelines, which was held in Montreal, Quebec, November 18 to 19, 2011. The meeting assembled a multidisciplinary group of family physicians, gastroenterologists, nurses, patients, foundation representatives, screening program administrators and researchers to discuss the development of a mechanism or strategy that would permit the collection of comparable data by all colorectal cancer (CRC) screening programs, which would not only support the needs of each program but also provide a national perspective. The overarching theme of the meeting was 'designing a national approach to computerized electronic data collection and dissemination for CRC screening that would improve knowledge transfer across the continuum of preventive health care'. The forum encouraged presentations on clinical, research and technical topics. The meeting fostered valuable cross-disciplinary communication and delivered the message that it is essential to develop a national health informatics approach for CRC screening data collection and dissemination to support provincial CRC screening programs.
\end{abstract}

Key Words: Colorectal cancer; Information technology; National registry; Report; Screening

ffective transmission of screening information is essential to the $\mathrm{E}_{\text {successful implementation of colorectal cancer (CRC) screening }}$ guidelines and to the evaluation of their uptake and impact on patient health outcomes. Increasingly, information technology (IT) is playing an important role in facilitating health care and health information management. Because most provinces in Canada have already begun (or will soon begin) CRC screening programs (1), there is an urgent need for IT solutions to support these programs. A pan-Canadian meeting was held in Montreal, Quebec, November 18 to 19, 2011, aimed at discussing the development of a national strategy for CRC screening data collection and dissemination throughout the continuum of care. The three major accomplishments of the meeting were that: it brought together stakeholders from across the nation to share expertise and 'brainstorm' this initiative; it encouraged stakeholder groups to identify their needs; and it created a steering committee to advance the development of a national health informatics strategy for CRC screening.
Un rapport sur le forum d'experts sur l'utilisation de la technologie de l'information pour faciliter l'adoption et les répercussions des lignes directrices sur le dépistage du cancer colorectal

Le présent rapport résume les débats du forum pancanadien d'experts sur l'utilisation de la technologie de l'information pour faciliter l'adoption et les répercussions des lignes directrices sur le dépistage du cancer colorectal, qui a eu lieu à Montréal, au Québec, les 18 et 19 novembre 2011. Ce forum a rassemblé un groupe multidisciplinaire de médecins de famille, de gastroentérologues, d'infirmières, de patients, de représentants de fondations, d'administrateurs de programmes de dépistage et de chercheurs pour discuter de l'élaboration d'un mécanisme ou d'une stratégie qui permettrait de colliger des données comparables dans tous les programmes de dépistage du cancer colorectal (CCR), lesquelles appuieraient non seulement les besoins de chaque programme, mais fourniraient également un point de vue canadien sur le sujet. Le forum visait à élaborer une approche nationale de la collecte et de la diffusion de données informatisées sur le dépistage du CCR qui améliorerait le transfert du savoir dans le continuum des soins de santé préventifs. Le forum favorisait des présentations sur des sujets cliniques, techniques et de recherche, de même que des communications interdisciplinaires précieuses. Il a fait ressortir toute l'importance d'adopter une approche nationale de l'informatique en santé pour la collecte et la diffusion de données sur le dépistage du CCR afin d'en soutenir les programmes.

${ }^{1}$ Department of Medicine, McGill University; ${ }^{2}$ Division of Clinical Epidemiology, Research Institute of the McGill University Health Centre; ${ }^{3}$ Division of

Gastroenterology, McGill University Health Centre, Montreal, Quebec; ${ }^{4}$ Division of Gastroenterology, Department of Medicine, McMaster University,

Hamilton, Ontario; ${ }^{5}$ Department of Family Medicine, University of Alberta, Edmonton, Alberta; ${ }^{2}$ Division of Gastroenterology, University of Toronto,

Toronto, Ontario; ${ }^{7}$ Colorectal Cancer Association of Canada, Montreal, Quebec

Correspondence: Dr Maida J Sewitch, 687 Pine Avenue West, V Building, Room V2.15, Montreal, Quebec H3A 1A1.

Telephone 514-934-1934 ext 44736, fax 514-934-8293, e-mail maida.sewitch@mcgill.ca 
TABLE 1

Characteristics of meeting attendees $(n=21)$

\begin{tabular}{lc}
\hline Characteristic & \\
\hline Age, years, mean \pm SD & $47.6 \pm 11.6$ \\
Female sex & $11(52.4)$ \\
Province/state of residence & \\
Quebec & $7(33.3)$ \\
Alberta & $4(19.0)$ \\
Ontario & $3(14.3)$ \\
Manitoba & $3(14.3)$ \\
British Columbia & $2(9.5)$ \\
Nova Scotia & $1(4.8)$ \\
Oregon (USA) & $1(4.8)$ \\
\hline
\end{tabular}

Data presented as $n(\%)$ unless otherwise indicated

quality and lack of linkage between databases, and discussed the challenges of integrating quality assurance into existing data collection systems. Issues regarding guideline implementation at the point of care were reviewed, including quality assurance for gastroenterologists, and determination of screening eligibility and completeness of endoscopy reporting for family physicians. Screening program leads and health IT experts discussed the existing screening processes and electronic systems used in Canada and the United States, some of which have difficulties with database access and linkages. The Canadian Cancer Society representative presented results from a survey that was conducted specifically for the purposes of the meeting, in which patients indicated that IT can improve their screening experience by providing access to information on colonoscopy scheduling (eg, update on wait time to colonoscopy) and screening test results, and by sending screening invitations and reminders.

\section{Stakeholder needs}

To promote 'buy-in' for a national health informatics strategy, stakeholder needs should be addressed from inception. Participants were divided into stakeholder groups to address the endoscopist $(n=9)$, family physician $(n=6)$ and patient $(n=6)$ perspectives. Each group was tasked with brainstorming the necessary components and functions of electronic solutions to support screening programs, and describing the steps to be taken for their actualization.

\section{Patients}

Patients and patient representatives believed that an online portal capable of scheduling appointments, sending reminders and providing test results, interpretations and recommendations promotes active patient involvement in screening and follow-up care activities. In addition, providing access to the portal delivers patient-centred care and facilitates dissemination of screening information, thereby improving the quality of the screening experience. Implementation of the portal must consider privacy laws in each province. The group believed that standardization of colonoscopy reporting would facilitate quality assurance, and that published institutional quality reports would assist patients with decision making regarding their screening and care activities.

\section{Family physicians}

Electronic solutions that support provincial screening policies would facilitate the identification of individuals eligible for screening and the timely distribution of invitations, reminders and notifications to patients and family physicians. Access to primary screening and diagnostic test results would increase family physicians' awareness of patients' screening and follow-up activities, allowing them to promote timely/appropriate follow-up and adherence to screening guidelines. Test results should be disseminated to family physicians in a standardized format with complete information. Implementation should start regionally and subsequently spread throughout Canada.
TABLE 2

Premeeting survey results for invitees $(n=18)$

\begin{tabular}{lc}
\hline Survey item & $\mathbf{n}(\%)$ \\
\hline Primary profession & $7(38.9)$ \\
Physician who sees patients & $3(16.7)$ \\
Researcher & $1(5.6)$ \\
Health informatics specialist & $1(5.6)$ \\
Nurse & $7(38.9)$ \\
Endoscopist & $6(33.3)$ \\
Other & $5(27.8)$ \\
Had a colonoscopy & $14(77.8)$ \\
Previously involved in health informatics projects & $18(100)$ \\
Believe there is need for colorectral cancer screening & \\
health informatics solutions & $12(66.7)$ \\
Believe there should be one colonoscopy data collection & \\
form for Canada & $16(88.9)$ \\
Believe some of the data should be made available to & \\
the public at large & \\
Who should have access to at least part of this information? & \\
Primary care physicians & $18(100)$ \\
Endoscopists & $16(88.9)$ \\
Patients & $13(72.2)$ \\
Other health professionals & $12(66.7)$ \\
Patient's family members & $4(22.2)$ \\
\hline
\end{tabular}

\section{Endoscopists}

From the service perspective, electronic systems can support provincial screening programs through enhanced data collection, clinical decision support and resource management. Endoscopy is an essential component of all provincial CRC screening programs and the IT endoscopy reporting module is necessary for assessing service access, quality and safety. Synoptic (standardized) reporting would facilitate the linkage of endoscopic reporting with pathology findings to further support quality analysis and follow-up recommendations. Existing electronic endoscopy reporting systems are limited in both customizability and interoperability. Establishing a national consensus on the development and maintenance of an endoscopic reporting data model based on terminology standards would encourage the availability of effective and affordable solutions in the marketplace.

\section{NEXT STEPS}

A six-member Steering Committee (DA, ANB, DM, PR, BS and MJS) was created to push the agenda forward. We have identified additional stakeholders that need to be included: patients, physicians, researchers, ethicists, provincial screening programs, laboratories, informatics consultants, hardware/software companies, professional associations, government, patient representatives and foundations. Given that standardized data collection and service quality assessment in colonoscopy were concerns raised by all three stakeholder groups, one of our next steps is to focus on the colonoscopy data model. The specific aims are to establish thresholds for colonoscopy quality indicators and to develop an electronic colonoscopy reporting model to support standardized data collection. A project for national colonoscopy synoptic reporting has recently received funding from the Canada Health Infoway Innovation Fund. Direct patient access to screening information and provider communication was emphasized as key to success, quality and sustainability. We plan to engage patients by developing questionnaires to solicit their feedback on patient-derived indicators of colonoscopy quality.

\section{REFERENCE}

1. Telford JJ. Canadian guidelines for colorectal cancer screening. Can J Gastroenterol 2011;25:479-81. 


\section{CONCLUSIONS}

The meeting provided the opportunity for experts to begin addressing the major challenges associated with the development and implementation of a national strategy for data collection and dissemination to support CRC screening. The meeting was well received and several individuals provided positive feedback such as:

...[it was] very successful in establishing some strategic priorities to improve quality, access and communication related to colon cancer screening and follow-up; and

...it was a good start to a difficult problem

All attendees endorsed the national approach to the development of health informatics solutions for CRC screening as a priority for Canada because it ensures the delivery of high-quality care. The momentum gathered from the meeting, the spirit of collaboration fostered among participants and the expertise of collaborators will help to push this initiative forward.
ACKNOWLEDGMENTS: This research was supported by a Knowledge Translation grant (\#4573) from the Canadian Institutes of Health Research. Maida J Sewitch PhD is a Checheur Boursier Junior 2 of the Fonds de recherche du Québec - Santé. The authors express their appreciation to all attendees of the Expert Forum: Stephanie Brien, McGill University Health Centre (Montreal, Quebec); Maria-Helena Dias, McGill University Health Centre; Catherine Dubé, University of Calgary (Calgary, Alberta); Rob Enns, University of British Columbia (Vancouver, British Columbia); Lee Fairclough, Canadian Partnership Against Cancer; Nigel Flook, University of Alberta (Edmonton, Alberta); Robert Hilsden, University of Calgary; Alan Katz, University of Manitoba (Winnipeg, Manitoba); Judy Logan, Oregon Health \& Science University (Portland, Oregon, USA); Donald MacIntosh, Dalhousie University (Halifax, Nova Scotia); Laura Plett, Canadian Cancer Society; Harminder Singh, University of Manitoba; Zhuoyu Sun, McGill University; Laura Sware, BC Cancer Agency (Vancouver, British Columbia).

DISCLOSURES: The authors have no financial disclosures or conflicts of interest to declare. 


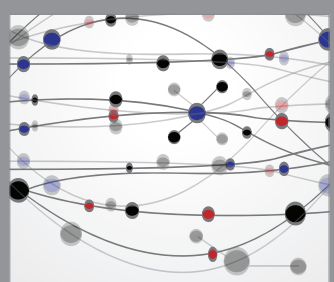

The Scientific World Journal
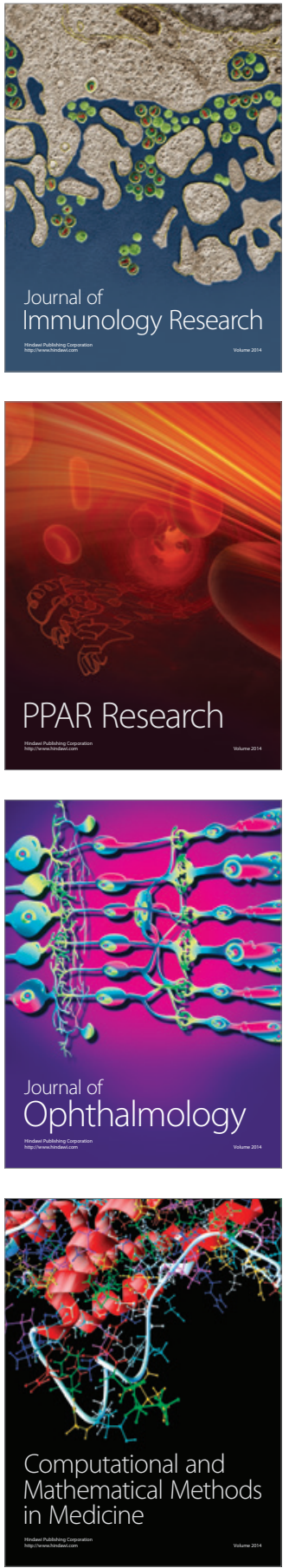

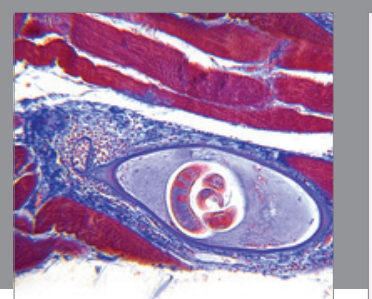

Gastroenterology Research and Practice

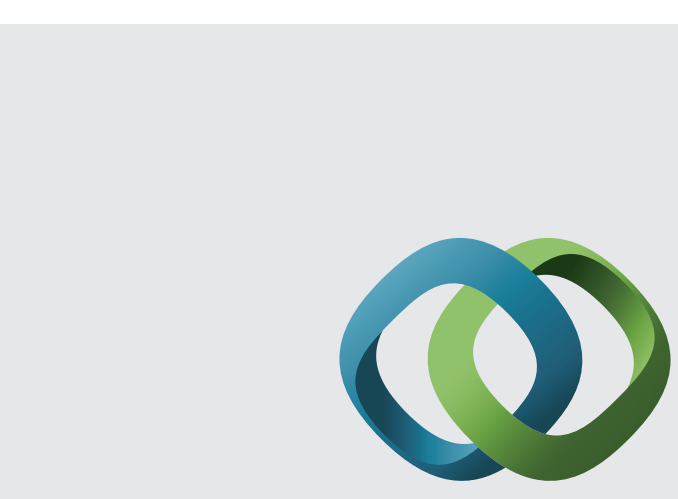

\section{Hindawi}

Submit your manuscripts at

http://www.hindawi.com
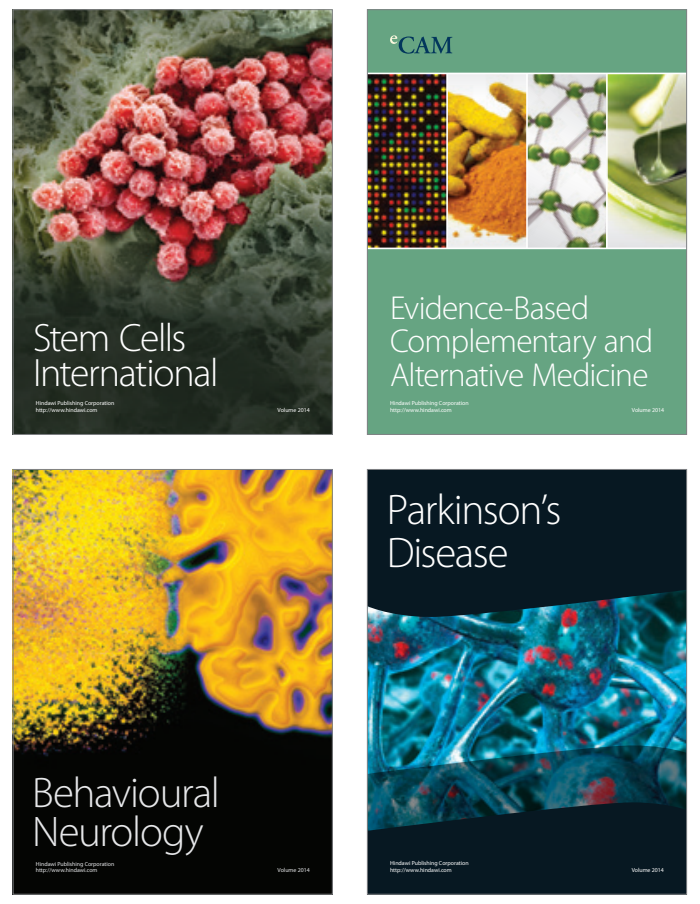
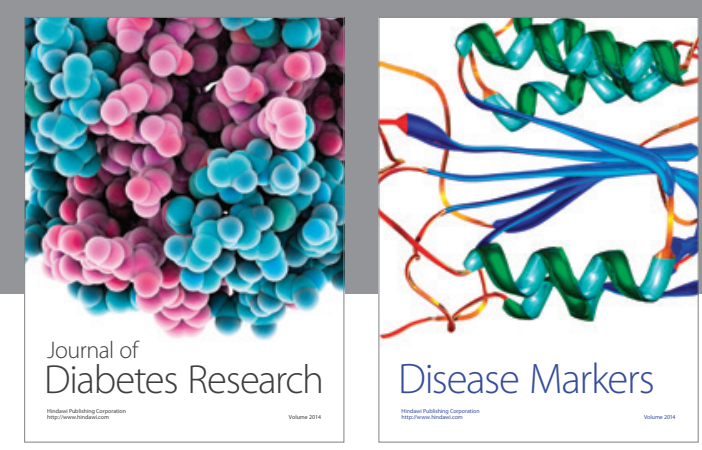

Disease Markers
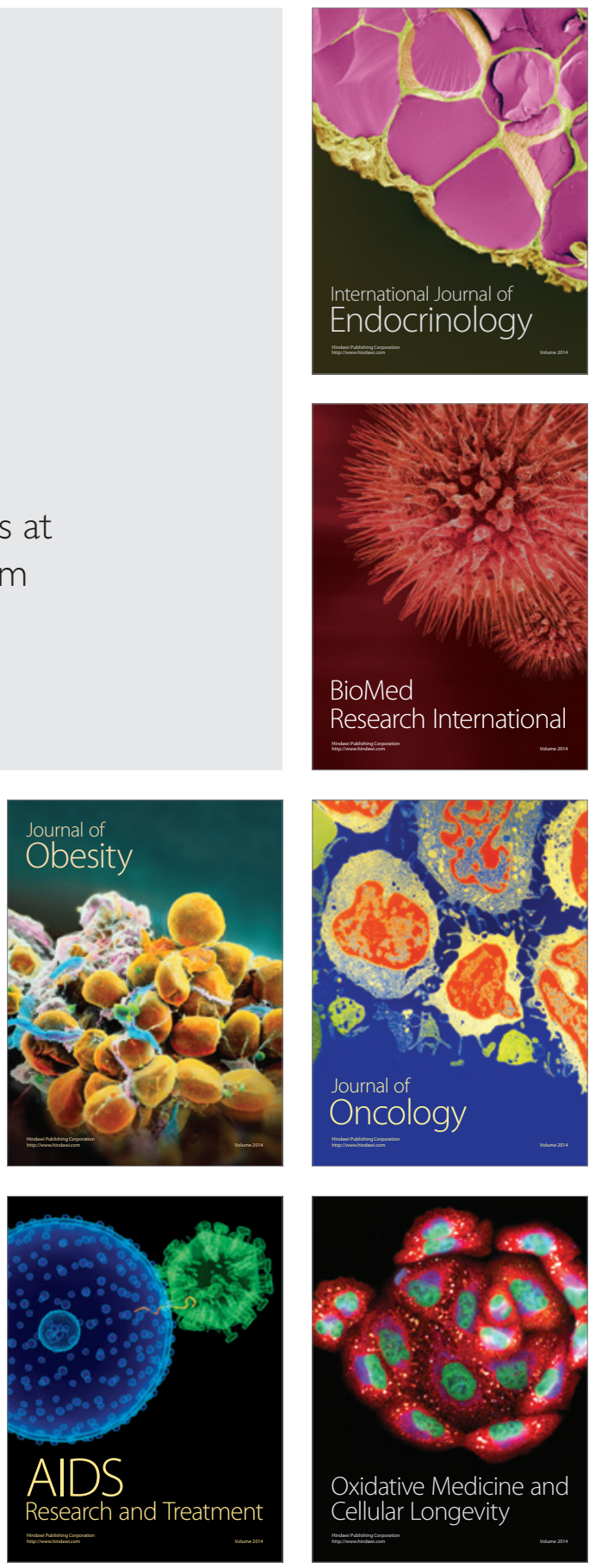